\title{
Outpatient service transformation; delivery of nF2F clinics in a COVID-19 era
}

\author{
Authors: Alice Cole, ${ }^{\mathrm{A}}$ Asim Khan, ${ }^{\mathrm{A}}$ Naveen Bhadauria, ${ }^{\mathrm{A}}$ Maurice Cohen ${ }^{\mathrm{A}}$ and Dev Mukerjee ${ }^{\mathrm{A}}$
}

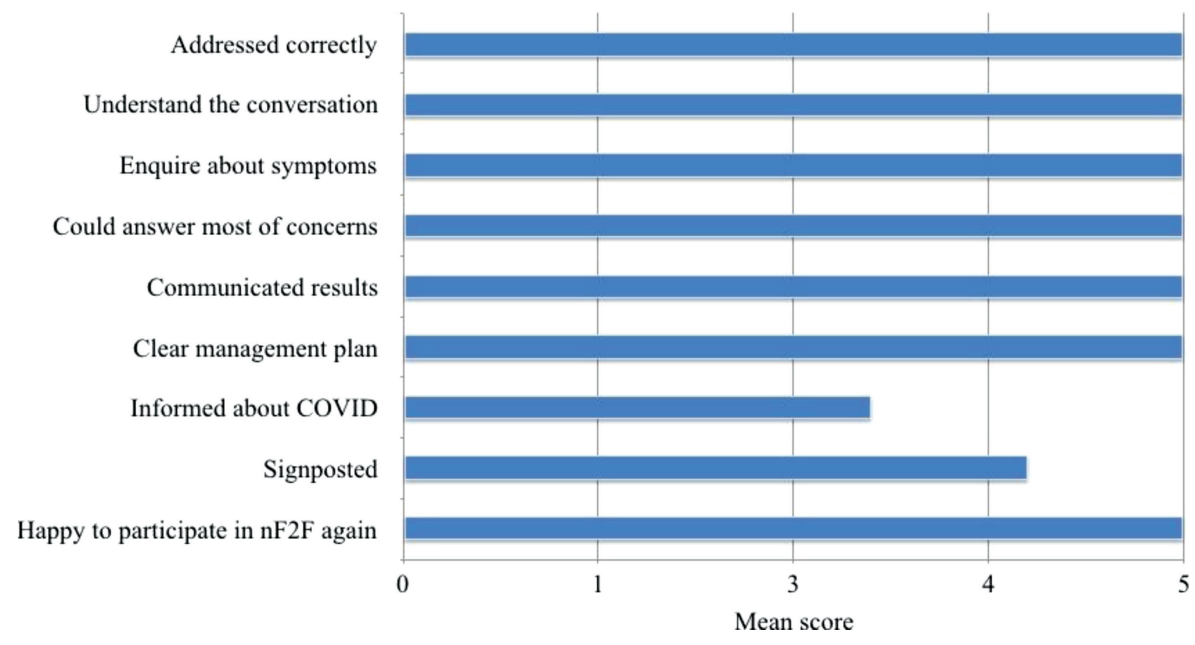

Fig 1. Patient feedback on $\mathrm{nF} 2 \mathrm{~F}$ clinics on a Likert scale.

\section{Introduction}

Non-face-to-face ( $\mathrm{nF} 2 \mathrm{~F})$ interactions have replaced many face-to-face interactions during the COVID-19 crisis. This has had a significant impact on the way clinicians deliver outpatient rheumatology care. In a London district general hospital setting, we wished to study the impact of this innovative model of care and assess whether $\mathrm{nF} 2 \mathrm{~F}$ interactions can be blended with face-to-face interactions in outpatient consultations in the post-COVID-19 era.

\section{Aims}

We aimed to develop a standard operating procedure (SOP) for nF2F clinics in order to deliver and maintain rheumatology outpatient services during the COVID-19 pandemic and we also aimed to perform a qualitative analysis using patient feedback questionnaires.

\section{Methods}

Patients were allocated to receive telephone consultations with triaging to allow for necessary face-to-face clinics. Serology or imaging requests were posted prior to the next appointment. Rapid cycle evaluation was carried out 8 weeks after initiation

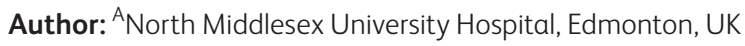

of the clinics. Ninety-six patients were contacted to complete a questionnaire with Likert scale questions to assess satisfaction.

\section{Results and discussion}

An SOP was developed to guide staff participating in $\mathrm{nF} 2 \mathrm{~F}$ clinics. ${ }^{1-3}$ Sixty-eight patients participated in the questionnaire. The clinics were well received, scoring highly (average 5/5) for satisfaction. Benefits included reducing travel time, cost and onthe-day waiting times. All patients had received their serology or imaging requests via post. The most significant barriers to $\mathrm{nF} 2 \mathrm{~F}$ was translation services, contingencies for which are included in our SOP. Thirty per cent of patients specified a preference to return to F2F clinics following the pandemic (Fig 1).

\section{Conclusion}

The COVID-19 pandemic necessitated a transformation of outpatient services to $\mathrm{nF} 2 \mathrm{~F}$ interactions. NF2F clinics have previously been trialled in smaller scales with success. ${ }^{4}$ Rapid cycle evaluation demonstrated that the vast majority of patients were successfully 'attending' their appointments and patients are satisfied with the service. We have demonstrated a successful move to virtual consultations in the midst of the COVID-19 pandemic which may now be incorporated into our outpatient service in the post-COVID era. 


\section{Conflicts of interest}

None declared.

\section{References}

1 Central and North West London NHS Trust. Video appointments: A guide for patients. CNWL, 2020. www.cnwl.nhs.uk/application/ files/5115/8643/3495/Video_appointments_A_guide_for_ patients.pdf [Accessed 31 July 2020].

2 British Medical Association. COVID-19: video consultations and homeworking. BMA, 2020. www.bma.org.uk/advice-and-support/ covid-19/adapting-to-covid/covid-19-video-consultations-andhomeworking [Accessed 31 July 2020].
3 General Medical Council. Remote consultations flowchart. GMC. www.gmc-uk.org/ethical-guidance/learning-materials/remoteconsultations-flowchart [Accessed 31 July 2020].

4 UCLPartners. Non face-to-face (virtual) clinics: examples and resources. UCLPartners. https://uclpartners.com/work/non-faceto-face-virtual-clinics-examples-and-resources [Accessed 31 July 2020]. 